\title{
Rare case of paratesticular solitary fibrous tumour (lipomatous hemangiopericytoma)
}

\author{
Yagil Barazani, MD, Basir Tareen, MD \\ Beth Israel Medical Center, Albert Einstein College of Medicine, Phillips Ambulatory Care Center, New York, NY
}

Cite as: Can Urol Assoc J 2012;6(3):E131-E133. http://dx.doi.org/10.5489/cuaj.11092

\section{Abstract}

A 26-year-old male presented with an asymptomatic 6-cm left paratesticular mass. Ultrasound and magnetic resonance imaging confirmed this mass as extratesticular, likely a tumour arising from the left spermatic cord. The mass demonstrated marked avid enhancement on post-contrast images, suggestive of a spermatic cord sarcoma. A left inguinal exploration was performed and gross examination of the mass revealed a well-circumscribed tumour with a discrete capsule separating it from the ipsilateral spermatic cord. The mass was resected without performing an orchiectomy and histology demonstrated a solitary fibrous tumour (lipomatous hemangiopericytoma), with minimal proliferative activity and negative margins. The occurrence of a paratesticular solitary fibrous tumour is exceedingly rare, with only a handful of case reports. We review the literature regarding this rare entity and discuss its diagnosis and management.

\section{Introduction}

While most masses within the scrotal sac are neoplasms of the testis, a small subset of these are extratesticular and arise from paratesticular tissues (structures of the spermatic cord, testicular tunics, and vestigial remnants). About 70\% of paratesticular tumours are benign, the most common of these being lipomas, adenomatoid tumours and leiomyomas. Less common benign tumours of the paratesticular region include fibromas, hemangiomas, neurofibromas, papillary mesotheliomas and cystadenomas. ${ }^{1}$ A variety of even more uncommon benign tumours have been reported in the paratesticular region; among the rarest of these is the benign solitary fibrous tumour (hemangiopericytoma). This report describes a case of paratesticular hemangiopericytoma, one of only several to date in the literature.

\section{Case report}

A 26-year-old otherwise healthy male was referred for evaluation of a left paratesticular mass. The mass caused no discomfort or local symptoms; it came to the patient's attention as a painless firm mass that enlarged over the course of six months. On physical exam, a 6-cm oval-shaped paratesticular mass distinct from the left testis was palpated. A scrotal ultrasound was performed initially, which confirmed an extratesticular mass $6.1 \times 5.5 \times 4.3 \mathrm{~cm}$, likely a paratesticular tumour arising from the left spermatic cord (Fig. 1). The mass was predominately hypoechoic with scattered hyperechoic foci and increased vascularity. The testes and epididymi were normal in size and echogenicity bilaterally.

Testis tumour markers were all normal [alpha-fetoprotein (AFP) 2.1, lactate dehydrogenase (LDH) 566, human chorionic gonadotrophin $(\mathrm{HCG})<2.0]$. A magnetic resonance imaging of the abdomen and pelvis further characterized this mass as a $4.7 \times 6.2 \times 5.9 \mathrm{~cm}$ tumour arising from the spermatic cord (Fig. 2). The mass demonstrated marked avid enhancement on post-contrast images, suggestive of a spermatic cord sarcoma. No evidence of pelvic or retroperitoneal lactic acid dehydrogenase was seen.

A left inguinal exploration was performed, during which the left testis and mass were delivered separately into the surgical field. On gross examination, the mass appeared well-encapsulated, with a smooth surface free of adhesions or tumour extension, allowing us to easily resect it from the ipsilateral scrotal wall and spermatic cord.

On histological examination, the cut surface of the mass was pink-tan, homogeneous and fleshy in appearance without any hemorrhage or necrosis. Microscopy (Fig. 3) revealed a $7.5-\mathrm{cm}$ solitary fibrous tumour (lipomatous hemangiopericytoma), with minimal proliferative activity as seen by $\mathrm{KI}-67<5.0 \%$ and 0/10 mitotic figures observed per high power field. Immunohistochemistry was as follows: CD34 + , BCL-2 +, SMA -, desmin -, S100 protein -. On 


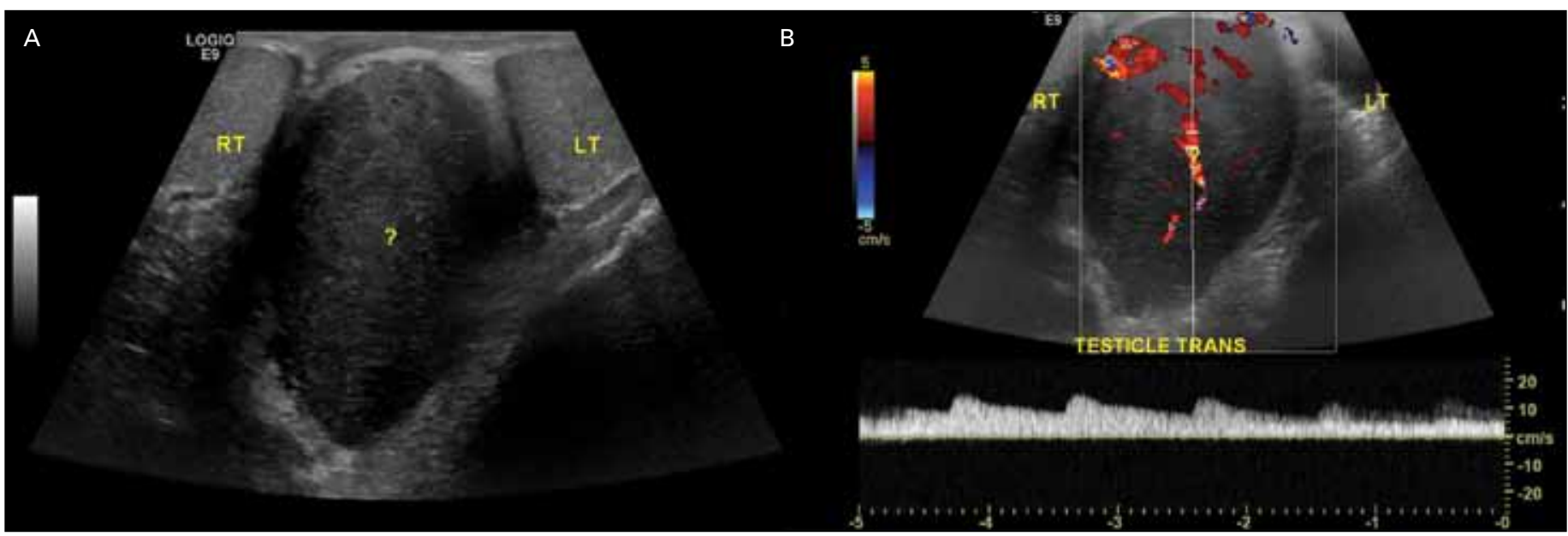

Fig. 1. Scrotal ultrasound (transverse view) demonstrating extratesticular mass arising from L spermatic cord, with (a) predominantly hypoechoic appearance with scattered hyperechoic foci and (b) increased vascularity demonstrable on color flow Doppler.

the basis of these histopathologic and immunohistochemical findings, the diagnosis of a paratesticular solitary fibrous tumour was made.

\section{Discussion}

Adult paratesticular tumours comprise a histologically diverse group of neoplasms originating from epithelial, mesothelial and mesenchymal elements in the paratesticular region. It has been estimated that $70 \%$ of paratesticular tumours are benign, the most common of these being adenomatoid tumours, lipomas and leiomyomas. Malignant tumours of the paratesticular region are less common, with sarcomas accounting for most of these. Published series of sarcomas have identified leiomyosarcoma $(32 \%)$ as the most common malignant soft tissue tumour in this region, followed by rhabdomyosarcomas (24\%) and liposarcomas (20\%). ${ }^{1-4}$

A number of very uncommon benign and malignant tumours have been reported in the paratesticular region. Among the rarest of these are hemangiopericytomas, typically low-grade neoplasms of pericytes and myofibroblastlike cells that are normally arranged around capillaries and venules. When present outside the central nervous system, the preferred terminology for these tumours is solitary fibrous tumours. These growths generally present as slow-growing, painless masses at any anatomic site; however, the lower extremities and retroperitoneum are most common. Less prevalent sites include subcutaneous tissues, as well as the pelvis, head and neck, and abdomen. Histologically, solitary fibrous tumours are characterized by numerous branching capillary channels and gaping sinusoidal spaces enclosed within nests of spindle- to round-shaped cells..$^{5-7}$ Intrascrotal solitary fibrous tumours are uncommon, with only a few cases reported in the paratesticular region. ${ }^{6-11}$ Histologically, these tumours have similar morphological features to those present elsewhere in the body.
Most solitary fibrous tumours are benign and present as well-circumscribed, slowly growing, painless masses. Surgical resection is curative in most cases. However, $10 \%$ to $15 \%$ of solitary fibrous tumours show aggressive behaviour and recurrences have been documented many years after resection. Given the small risk of local disease recurrence and metastasis, long-term follow-up is sufficient in the absence of further adjuvant therapy. ${ }^{7,12}$

\section{Conclusion}

While solitary fibrous tumours are more common elsewhere in the body, very few case reports have been published of paratesticular origin. The few cases described in the literature do not address long-term follow-up of these tumours, and therefore there is little evidence on which to base treat-

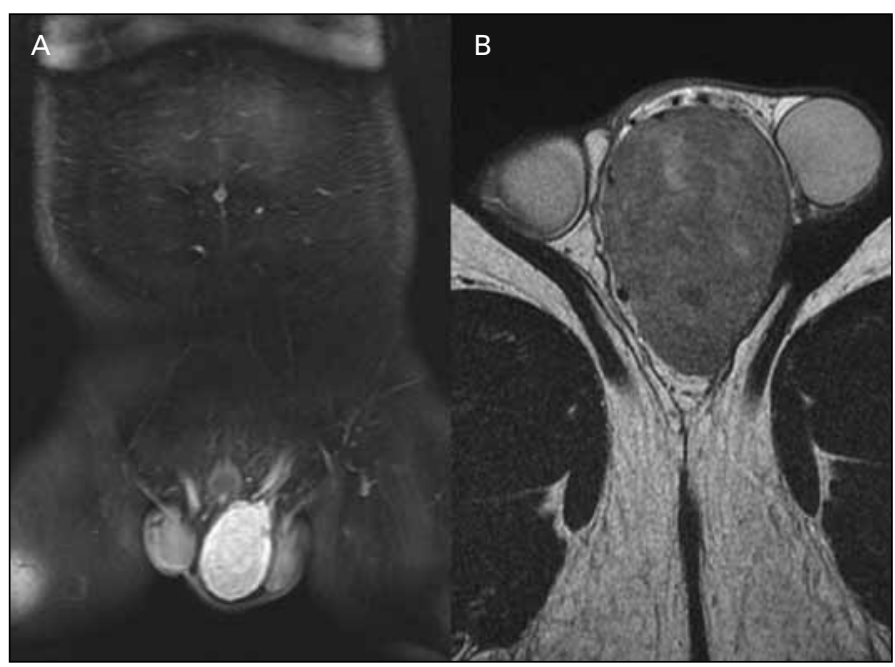

Fig. 2. Magnetic resonance imaging demonstrating tumour $4.7 \times 6.2 \times 5.9 \mathrm{~cm}$ arising from left spermatic cord. (a) coronal view showing marked avid enhancement on post-contrast images, (b) sagittal view of heterogenous mass with prominent feeding vessels noted superiorly. 




Fig. 3. Hematoxylin and eosin stain demonstrating bland spindle cell tumour with vascular spaces, some showing "staghorn" configuration.

ment. However, given their behavior at other anatomic sites, paratesticular solitary fibrous tumours with low proliferative activity have little potential for local recurrence or metastatic spread. Thus, our current approach will be to monitor the patient by means of serial physical exams and scrotal ultrasounds to rule out disease recurrence.

Competing interests: None declared.

This paper has been peer-reviewed.

\section{References}

1. Khoubehi B, Mishra V, Ali M, et al. Adult paratesticular tumours. BJU Int 2002;90:707-15. http:// dx.doi.org/10.1046/j.1464-410X.2002.02992.x

2. Wein AJ, ed. Campbell-Walsh Urology. 9th ed. Philadelphia, PA: Saunders Elsevier; 2007: ch. 29.

3. Salako AA, Onakpoya UU, Osasan SA, et al. Testicular and para-testicular tumour s in south western Nigeria. Afr Health Sci 2010;10:14-7.

4. Pérez JC, Licham MA, Godoy MP, et al. Adult paratesticular sarcomas. Management and evolution of the disease. Actas Urol Esp 2009;33:639-45.

5. Kumar V, Abbas AK, Faust N, et al. Robbins and Cotran Pathologic Basis of Disease. Professional Edition, 8th ed. Philadelphia, PA: Saunders Elsevier; 2010; ch. 11.

6. Honeck P, Ströbel P, Michel MS, et al. Solitary fibrous tumour of the testes (SFT). Aktuelle Urol 2008;39:305-8. http://dx.doi.org/10.1055/s-2008-1038162

7. Lee GE, Rha SE, Byun JY, et al. Paratesticular solitary fibrous tumour : a rare cause of a hypervascular extratesticular mass. J Ultrasound Med 2011;30:279-81.

8. Varela R, García HA, Cortés V. Testicular hemangiopericytoma, solitary fibrous tumour : a very rare case. Arch Esp Urol 2010;63:816-9.

9. García Torrelles M, Beltrán Armada JR, Santolaya García I, et al. Solitary fibrous tumour of the tunica vaginalis testis. Arch Esp Urol 2006;59:186-9.

10. Márquez Moreno AJ, Vicioso Recio L, Castro León A, et al. Paratesticular solitary fibrous tumour . Arch Esp Urol 2001;54:716-8.

11. Jones MA, Young RH, Scully RE. Benign fibromatous tumour s of the testis and paratesticular region: a report of 9 cases with a proposed classification of fibromatous tumour $s$ and tumour -like lesions. Am J Surg Pathol 1997;21:296-305. http://dx.doi.org/10.1097/00000478-199703000-00005

12. Mason RJ, Broaddus VC, Martin TR, et al. Murray and Nadel's Textbook of Respiratory Medicine. 5th ed. Philadelphia, PA: Saunders Elsevier; 2010; ch. 75.

Correspondence: Dr. Basir Tareen, Physician-in-charge, Urologic Oncology, Beth Israel Medical Center, Assistant Professor, Albert Einstein College of Medicine, Phillips Ambulatory Care Center, Suite 3A, 10 Union Square East, New York, NY 10003; BTareen@chpnet.org 